\title{
Kedi ve köpek korpus siliyaresinde bağ doku mast hücreleri ve farklı boyanma özellikleri
}

\author{
Ziya ÖZCAN \\ Ankaral Üniversitesi. Veteriner Fakiultesi. Histoloji-Embriyoloji Anabilim Dalı. Ankara
}

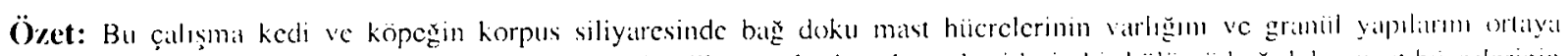

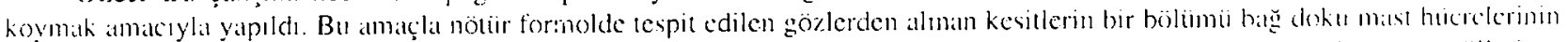

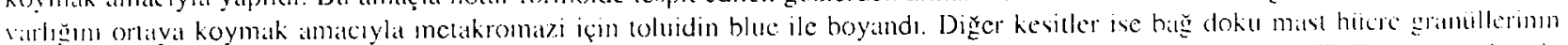

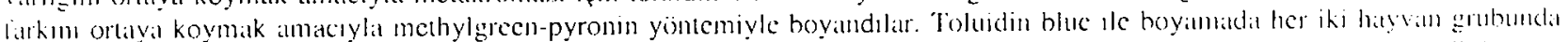

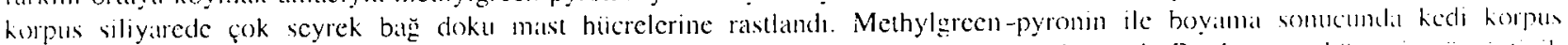

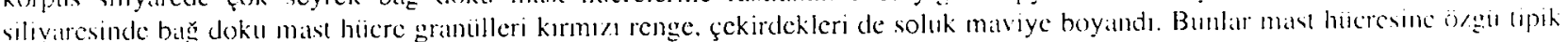
vapulan ile farkedildiler. Köpek korpus siliyaresinde ise bag doku mast hücreleri methylgreen-pyronin ile boyiumadalau. Somuctil.

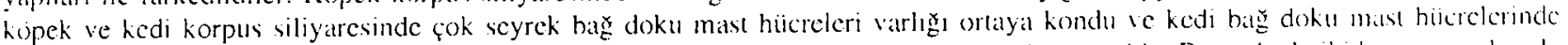

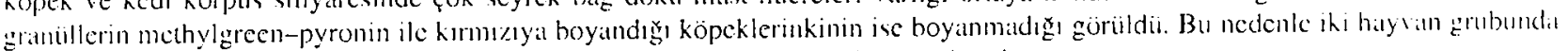
korpus siliyare balı̆ doku mast hüicre graniil içeriklerinin farklı olabileceợi ortaya kondu.

Anthtal kelimeler: Bä doku mast hiucresi, kedi, korpus siliyarc. köpek

\section{Presence and different staining properties of connective tissue mast cells in corpus ciliare of cat and dog}

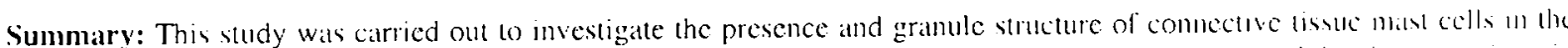
corpus ciliare of cat and do: In order to demonstrate the presence of connective tissue malse cells, some of the tinste sections it

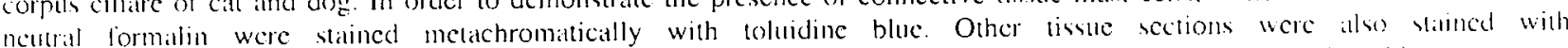
methylgeen pyronin method to demonstrate the different mast cell granules. During staining with toluidine hlue. very ratre connclive lisste mast cells were found in the corpus ciliare of both animal groups. After staining with methylgercen-pyronin. the connective tissue mast cell gramules were stained in red and must cell mucleus in pale blue in the call corpus ciliarc. These were noticed by the typical structure of mast cells. In the dog corpus ciliarc. connective tissue mist colls were not biancil with methylgrecn-pyronin. As a result. presence of very rare connective lissue mast cells in the corpus ciliatre ol call alnd dis! were demonstrated. Also. it wats observed that the gramules in the cat connective tissue mast cells were stanted in led by

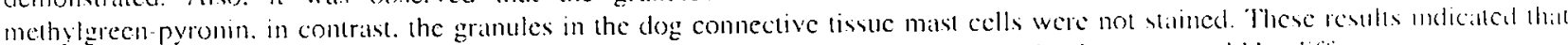
the granule structure of connective tissue matst cells in the corpus ciliare of these two animal group could he dificremt

Key words: Cal, connective tissue mast cell, corpus cilitre, dog

\section{Giriş}

Korpus siliyare gözüin orla katmanmm ön bölünüuii iris ile hirlikte oluşurur. Enine kesitte üçgen şeklinde göriiliur. Bir yüzii camsı cisim ile, bir yüzü sklera. ïçüncii yiir ise nercek ve arka kamara ile ilişkilidir. Silier kaslar. elastik iplikler. kollagen iplikler, damarlar ve melanositlerden zengin gevşck bağ dokusundan oluşur (10).

Mast huicrelerinin mukozal mast hücresi ve bağ doku mast hücresi olmak üzcre iki tipi tanımlanmışır. Bu lanmulama mast hücrelerinin morolojik, biyokimyasal ve fizolojik ozzelliklerine bağlı olarak yapılnuşur $(4,5,11)$.

Insan gözuinde yaprlan bir çalışmada korpus silivarede kaslar arasında mast huicrelcrinin bulunduğu bilclirilmişlir (15). Immmun hüicre dağılımı konusunda yapılan çalışmada birçok laboratuvar hayvanında anterior uveada (korpus siliyare ve iris) mast hiicrelerine rastlanmadığ bildirilnekıcdir (16). Tavuk fötüs gözunde yapılan çalişmada, gelişmennin 14. güinünden itiharén mast hice. relerinin sadece irisin ön yibzinde ve peklincal ligannentec göruildügui bildirilmektedir (17). Tavşan girande yapılan bir çalş̧mada ojzellikle siliyer mantularda mast hucrelerj gözlenmişlir (22). Normal ve enfekte ratlardar yapnlan hir çalışmadda normal ratlarm korpus siliyaresinde çok az sayida mast hiicresine rastlandig్ bildirilmekledir (1). Ral. kobay ve gelincikte korpus siliy arede siliger w/amulanda à sayıda masi hicresi gözlenmiştir (21).

Normal köpek gözlerinde mast hücrelermin retinat. iris. korpus siliyare, korioid. skleral ve kornciada bulundukları sayısal olarak ortaya konulmusilur (14).

Ayruca, köpek derisinde (6). Ankaral keçisinin all solunum yollarmda (12), inck uterusunda (7). lavuk ve bll dircm derisinde (1.3) mast hiicreleri ìerinc çalışl muşır. 
Gö\% yangllarında mast hiicreleri histamin ve heparin salghlarlar. Immun yantla etkileyici hiicreler olarak yer alıliar. Antijenle etkileşimleri sonucunda, granüllerin erimesiyle histamin. prostaglandin, serotonin gibi maddeler salgelanur (20).

Mast huicreleri yerleşimlerine göre yuvarlak, oval veya mekik şcklinde görüilcbilen yaklaşık 12-15 mikron büyliklükte hücrelerdir. Merkezi veya eksantrik olarak yerleşmiş segmentsiz küçuik yuvarlak ya da oval hir çekirclegge ve graniillerle dolu genis bir sitoplazmaya sahiptirler (9).

Bağ doku mast hüicrelerinde histamin, yiiksek oranda süllath proleoglikana ve heparine bağl olarak bulunur. Bu huicreler metakromatik boyalarla kolayca boyandığından "tipik" mast hücreleri olarak adlandırılır: wluiclin bluc ile nötür pH'da metakromatik olarak boyanabilirler (2.19). Gevşek bağ doku içerisinde bulunan masi hücreleri. içerdiği glikozaminoglikanlar nedeniyle hazik anilin boyalarn (coluidin blue gibi) ile metakromazi izelliği gösterirler (15). Toluidin blue ile mast hücre graniilleri. boya konsantrasyonuna. asitlik durmmuna ve bo yama zamamma göre koyu mor-kımızı renge boyanır Cckirdek mavi. sitoplazma ise açık maviye boyanır. Toluidin blue ile $\mathrm{pH} 0.5^{\circ}$ de bağ doku mast hücreleri koyu mor renkte boyanir (5).

Mast huicreleri. methylgreen-pyronin yöntemi ile boyandiklarmula pironinofili göstcrebilirler, ancak morfolojik $6 /$ ellikleriyle plazma hiicrelerinden ayırt edilebilir (3). Mukozal masi hücresi graniillerinin formaldehit tespitine duyarlı, bağ doku ması hücresi granuillerinin ise dirençli olduğu bildirilnektedir $(4,8)$. Sığırların akciğer ve derisinde yapılan falışmada bağ doku mast huicrelerinin yapısınu ve granül içeriklerinin formol tespitine dirençli ol duklan ortaya konmuşurur (8). Bu çalışmada normal kedi ve kojpek korpus siliyaresinde bulunan bas doku nast hiicrelerinin ve graniil içeriklerinin boyanma özelliklerinin belirlenmesi anıaçlanmuştır.

\section{Materyal ve Metot}

Bu çalışmada, Ankara Üniversitesi Veteriner Fakullesi kliniklerine ötanazi amaçlı getirilen ve herhangi bir gö sor sorunu bulummayan. belirgin bir ırk özelliği göstermeyen kedi ve köpekler kullanıldı. Yedi köpek (3 dişi, 4 crkek) ve 6 kedi ( 4 dişi. 2 crkek) gözii matcryal olarak kullanıld1. Kullanılan bu hayvanlarnn hepsi erişkin ve de

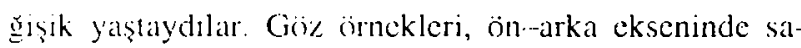
gitill bir şekilde tan ortiıdan ikiye aynlıp \%10 nöluir for molde 24 siat tespil edildi. Yskama. dehidrasyon. metil hemraat. ben\%ol aşamalarmolan sonra paraplasta blok- landılar. Köpek ve kedi gözii bloklarmdan alı mikronlık seri kesitler alınd. Bu seri kesitler birer atlamalı olarak Mc Ilvaine'nin sitrik asit disodyum fostat tamponunda hazurlanan \%0.5 lik toluidin blue $(\mathrm{pH} 4)$ ile: (5). diğer ke sitler de methylgreen-pyronin yönteni ike (18) boyands$\operatorname{lar}$

\section{Bulgular}

$\% 10$ nötuir formol tespitli @ِö hloklalmndan almaı seri kesitlerde köpek ve kedi gözui korpus silivarelurinde toluidin blue ile boyamada bağ doku malst häcrelerine çok seyrek olarak rastlamıldı.

Köpek ve kediden alman seri kessllerde bağ doku mast hücrelerinin granülleri metakromał izclliğ gös tererek boyandılar. Formol tespitine dirençli olan bu mast hücrelerinde sitoplazmada granüller mor renkli. çekirdek ise soluk mavi renkic göründuiler (Sckil I ve 2. oklar) Ayn bloklardan alman seri kesitlerde kijpck korpus siliyaresinde methylgreen-pyronin yönlemi ile bağ doku mast hïcrelerinin boya almadıklarn gioklendi. Falkall. kedi gözii bloklarndan alınan seri kesitlerin methylgereen pyronin yöntemi ile boyanmasmeda bu tuir mast hiicreleri nin siloplazmalarmda granuillerin kımm\%rya. çckiddckleri nin isc maviye boyandığ gözlendi (Şekil 3. oklar). Pironinofili gösteren bu hücreler, sitoplazmalammn gra

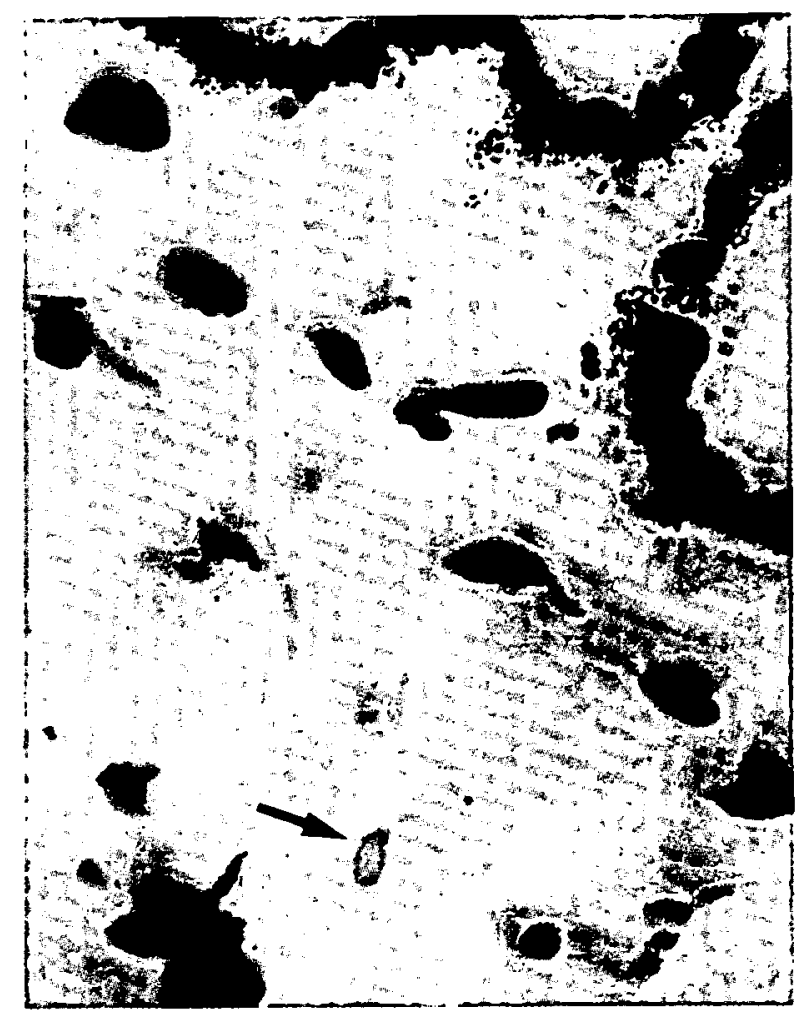

Şekil 1. Köpekte korpus silivarede göriilen mast hibresi fok! Toluidiu bluc. $\times 750$

Figure 1. Mast cell in the corpus ciliare of dore (arrow). Toluidine bluc. $\times 750$ 


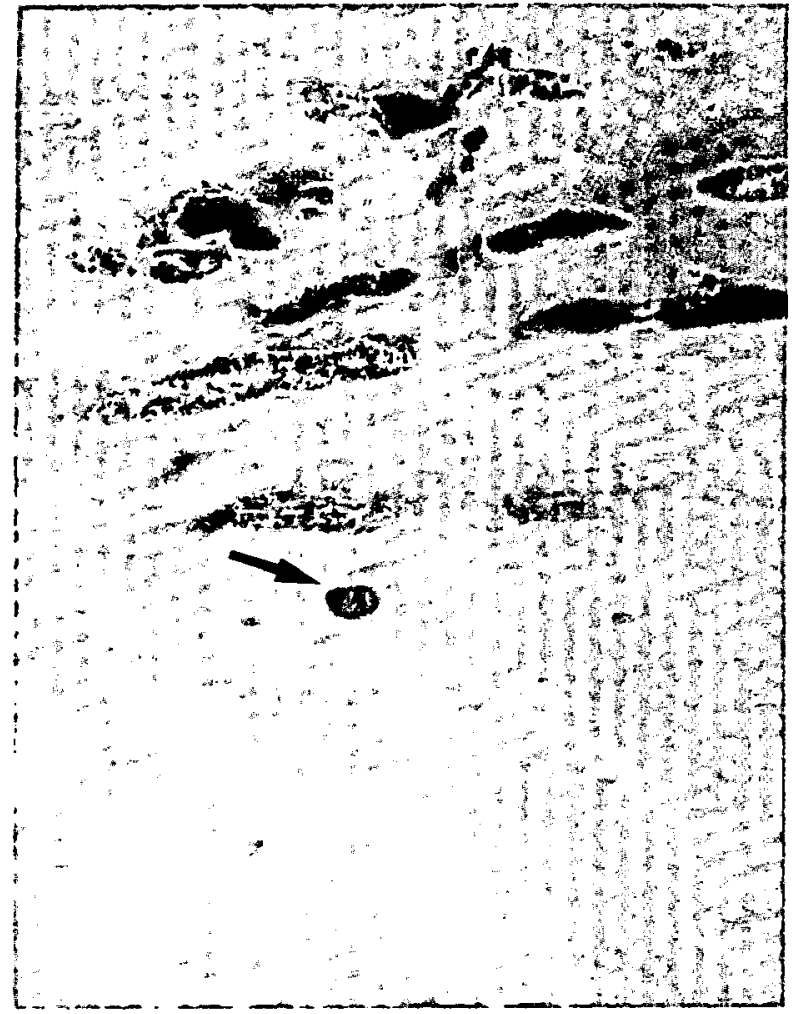

Şchil 2. Kedide korpus siliyarede göruilen mast hücresi (ok). Toluiclin bluc. $\times 750$

Figure 2. Mast cell in the corpus ciliare of call (arrow) Toluidine bluc. $x$ 750

nuillü görünümii, çekirdeklerimin de homojen maviye bovanmalan ile mast hücrelerinin özclliklerini gösterdiler.

\section{Tartışma ve Sonuç}

Gözün korpus siliyaresinde, muskulas siliyaris ve bunlatın arasım dolduran gevşck bağ doku alanları, hayvan lürlerine göre farkh bir yapıdadır. Buna bağlı olarak. bağ doku içerisinde damarlar, sinirler, bağ dokunun ipliksel ve huicresel yapıları hulunnaktadır. Bağ dokunun hücreleri olan mast hiicreleri de bağ dokulu alanlarda farklı niktarlarda bulunabilir.

Insan gözü korpus siliyaresi üzerinde yapılan bir çal1şmada siliyer kaslar arasında mast hücrelerine rastlandığ bildirilmekledir (15). Yine çeşitli hayvan türleri iizerinde yapılan çalışmalarda, tavuk fötüslerinde 14. günden itibaren mast huicrelerinin, irisin ön yüzünde ve pektineal ligamentte gözlendiği bildirilmektedir (17). Tavşanlarda özellikle siliyer uzantılarda mast hiicrelcri gِörülmüiştür (22). Normal köpek gözlerinde ise uveanın ön bölümüinde mast hücrelerinin varlığı ortaya konmuştur (14). Ayrica bazı laboratuvar hayvanlarmun korpus siliyaresinde mast hücrelerine rastlamlmadiğ bildirilmckledir (16). Literatuir taramassnda bu konuda kedi gözünde yaupılan bir çalışmaya rastlanılamadı.

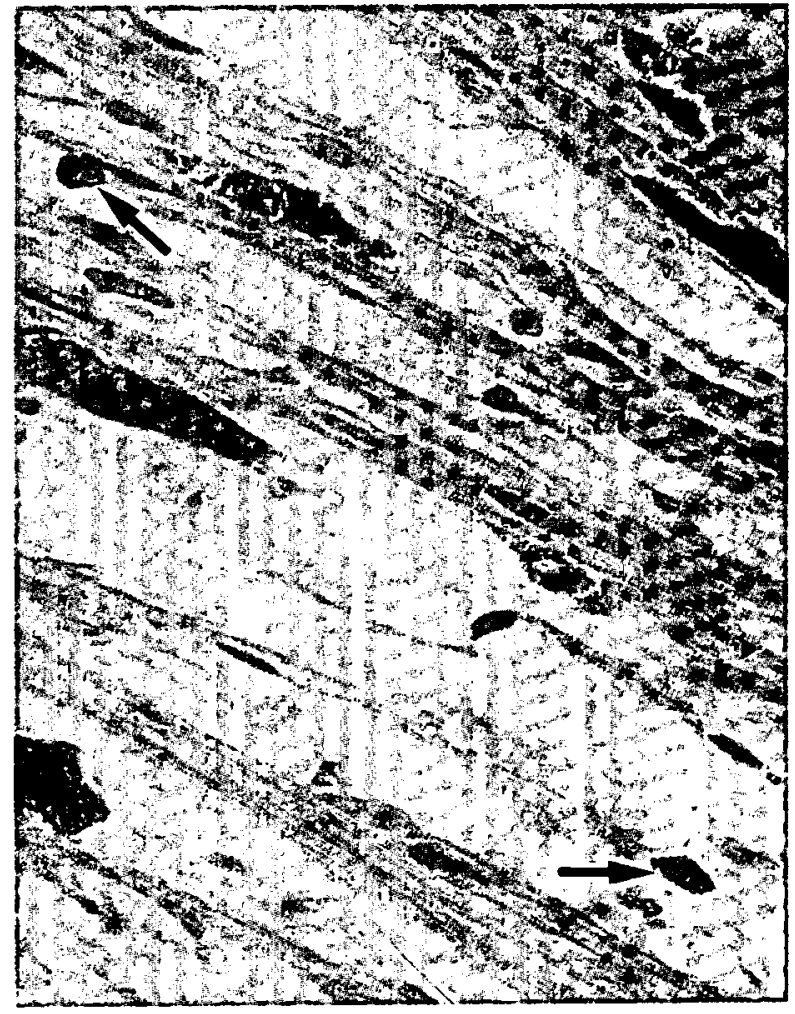

Sekil 3. Kedide korpus siliyarede mast hiicreleri (oklan). Methylgreen-pyronin. x 750

Figure 3. Mast cells in the corpus ciliare of cial (arrows). Methylgrcen-pyronin. $x 750$

Bu çallşnada köpck ve kedilerin korpus siliyarelerinde, siliyer kaslar arası ve epilel alı bağ dokulu alanlarda çok seyrek olarak bağ doku ması huicrelerinc rastlandı. Mast hücrelerinin varlığ ile ilgili çalısmalauda bu hücrelerin ayrımı yapilmaksim total degerlendimeles yapılmışur (14-17.22). Araşurma hulguları. korpus si liyarede mast hücrelerinin varlığ ile ilg̣ili çalışmalarla (14.15.17,22) paralellik göstermekledir

Yuvarlak, oval veya mekik şekilli. yakliışık 12-14 mikron büyüklükte, merke\%i ve cksantrik şckirdeğc sathip olan mast hiicrelerinin sitoplazmass granuillerle doludur (9). Çalışanan bulguları da bu litcrattir verileri ile paralellik göstermektedir.

Mast hücre granïlleri toluidin hlue ile melakromari özelliği gösterirler (2.5). Metakromazinin rengi boya konsantrasyonuma, asitlik durumuna ve boyama zamamma göre değişmekıedir (5). Bu çalışmada dal toluidin blue ile metakronazi özclliği giozlendi. Mast hijcreleri methylgreen-pyronin yöntemi ile boyandsklammda pironinolili gösterebilirler. Ancak, morfolojik ozellikleri ile plarma hücrelerinden ayrlabilirler (3). Bu f̧alışmanm kedi ve kïpeğe ait kesitlerinin methylgreen-pyronin youncmi ile boyanmasinda, kedilerde korpus siliyarede rastlanan bağ doku mast hücreleri çok iyi pironmotili gösterdikleri halde küpek korpus siliyaresindeki mast huicrelerinde pi. 
ronmofili gözlenemedi. Bu yönüyle köpck korpus siliyaresindeki bağ doku mast hiicrelerinin granïl içeriklerinin farkh olabileceğ d diişüiniilmektedir.

Sonuç olarak. köpek ve kedilerde gözün korpus silivaresinde hağ doku içerisinde a\% salyıda bağ doku mast hücresi bulunmaktadır. Bag doku mast hücrelerinin pironinofili ö»llikleri köpek ve kedilerde farklı olarak orlalya çıknakıadır

\section{Kaynaklar}

1. Allansmith MR, Baird RS, Kashina K (1979): Mast c.rlls un ocular tissues of normal rats and rats infected with Vippostromis/us brasiliensis. Invest Ophthatmol Vis Sci. 18. $863-867$

2. Atkins FM, Friedmen MM, Subba Rao PV, Mctealfe DD) (1985): Interactions between mast cells. fibroblast and connective disue components. Int Archs Allergy Appl Inmunol. 77.96-10?.

3. Culling CFA. Allison RT, Barr Wr (1985): Cellulu Pathelegey Technique. Fourih ed. Butterworth and Co Lad. london.

4. Lnerback 1. (1966): Mast cells in rat gastrointestinal mucrect. I. Elfectof fixation. Acta Path Microbiol Scindinalv. 66. $289 \cdot 312$

5. Lnerback $\mathrm{L}$ (1960): Mast cell in sastrointe stinal mucosa: 11. Die binding and metachromatic properties. Actal Path Microbiol Scindinat. 66. 303-312.

6. Eren $\ddot{\mathrm{U}}$ (20)(0) : Koipetk derisinde mast hücreleri. Ankara Uim Vot Fak Derg. 47. 167-175

7. Lren $\ddot{\mathrm{U}}$, Aștı RN, Kurtdede N, Sandikeı M, Sur E (1999): hek utertusunda mast hiccrelerinin histolojik re hiswhimbasal rizellikleri re mast hüre heterojentuesi. T I Anim Sci. 23. Suppl 1. 193-2011.

S. Hunt TC, Campbell A.M, Robinson C, Holgate ST (1991): Structural and secretory charactertstics of bovine lum: and skin mast cells: evidence forr the existence of helerogenteity: Clin Exp Allergy. 21, 173-189.

9. Johannes AG, Rhodin MD (1974): Rhodin Histology). A Text and Athas. New York Medical College. London.

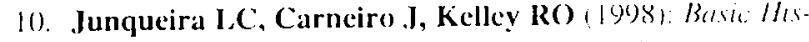
tology: Nineth ed. Appleton and Langec. Stambiont.

11. Kitamura Y, Kanakura Y, Sonoda S, Asai H, Nakano I (1987): Mutual phenotypic changes between combective hissue type and mucosal mast cells. Int Archs Alcrgy Appt Immunol. 82. 244-248.

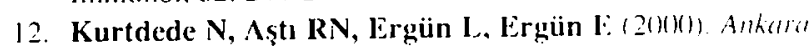

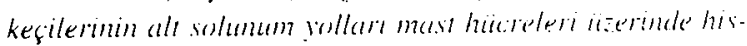

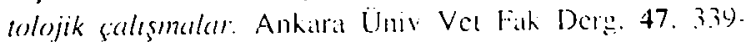
349.

13. Kurtdede N. Yörük M (1995): Tarak ie helderem derisinde mast hiicrelerinin morfologik ie histemestik incelenmesi Ankara Unir Val Fak Dorg. 42. 77-83.

14. Louden C, Render JA, Carlton WW (19)(1): Mast cell numbers in normal and slatucomatous anine reses Am I Vet Res. 51.818.819

15. May CA (1998): Mast well heteresenteing in the humem weet. Histochein Cell Biol. 112. $381-380$

16. Mc Menamin P(; (1997): The distributom of immune cells in the aveal tract of the normal eye. Eyc. 11. 18.3-193.

17. Oliani SM, (jirol AP, Smith RL, (1995): Gill functum bet

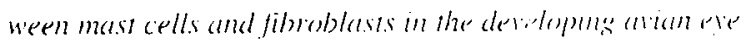
Actia Anat (Bascl). 154. 267-271

18. Romeis B (1968): Mikroskopische Technik. R Oldentusur: Verlag. Minchen.

19. Salman $\mathbf{N}(1901)$ : Temel Allerji. Litusil Allorji ve Klimk Lmınunoloji Dernç̆gi. Ankillia

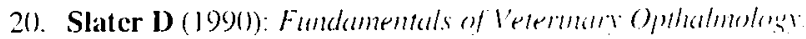
Second cd. Sillunders. Philixtelphial.

21. Smelser GK. Silver S (196.3): The distributum of mast cells in the normal ere. A method of sind Exp Lye Res. 2. 134-140).

22. Stenback $\mathbf{H}$, Krootila K, Palkama $\Lambda$, Lusitalo H [ [) 2) 1:

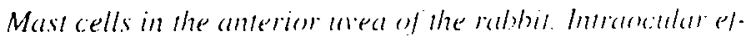
fects of compound $48 \mathrm{~S} 80$ in the rablit. Exp Eyc Res. 54. 247-252.

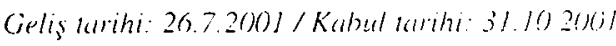

Yaßışma adresi:

Doç. Dr. Ziyai Özän

Ankara Üniversitesi. Veceriner Fithiilteri.

Histoloji-Embriyoloji Anabilim Dill.

(06110) Dışkipı. Ankira 